\title{
TCR-CD3 $\zeta$ gene expression profile in patients with rheumatoid arthritis and correlation with disease activity
} Abeer Abdelati ${ }^{\mathrm{a}}$, Rehab Elnemr ${ }^{\mathrm{b}}$, Ahmed Ismail ${ }^{\mathrm{a}}$, Marwa Gamal-Eldeen ${ }^{\mathrm{c}}$


Medicine, ${ }^{b}$ Department of Physical Medicine, Rheumatology and Rehabilitation, 'Department of Clinical and Chemical Pathology, Faculty of Medicine, Alexandria University, Alexandria, Egypt

Correspondence to Rehab Elnemr, Lecturer Department of Physical Medicine, Rheumatology and Rehabilitation, Faculty of Medicine, Alexandria University, Alexandria, Egypt. Tel: +20128151 0109;

e-mail: hobaelnemr@hotmail.com

Received 4 February 2019

Accepted 8 May 2019

Egyptian Rheumatology \& Rehabilitation 2019, 46:262-268

\begin{abstract}
Objective

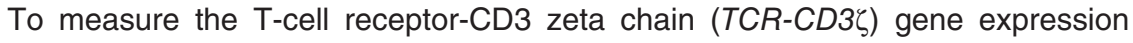
profile in a cohort of patients with rheumatoid arthritis (RA).

Patients and methods

A case-control study on 150 consecutive RA patients diagnosed according to 2010 ACR/EULAR criteria and 150 matched healthy controls without a family history of RA or other autoimmune diseases. RA patients with other autoimmune diseases, viral hepatitis $\mathrm{B}$ or $\mathrm{C}$, malignancy or hematological disorders were excluded from the study. All participants were subjected to history taking, clinical examination, assessment of disease activity (in RA patients) using Disease Activity Score-28 and Health Assessment Questionnaire, routine laboratory investigations, inflammatory marker levels, serological tests, as well as molecular analysis for TCR-CD $3 \zeta \mathrm{mRNA}$ expression by quantitative real-time PCR.

Results

TCR-CD3 $\zeta$ gene expression was significantly lower in RA cases than in controls $(P<0.05)$. Expression of $T C R-C D 3 \zeta$ has shown a significant negative correlation with RA disease duration, rheumatoid factor, and erythrocyte sedimentation rate $(P<0.05)$ in RA cases. The level of $T C R-C D 3 \zeta$ also showed a significantly less expression in patients with positive rheumatoid factor.

\section{Conclusion}

Our results demonstrated a lower expression of TCR-CD3 $\zeta$ in RA patients than in healthy controls. We suggested that CD247 gene downregulation might contribute in the susceptibility to RA and help understanding the pathways responsible for deficient T-cell responses in RA patients.
\end{abstract}

\section{Keywords:}

CD247, gene expression, PCR, rheumatoid arthritis, T-cell receptor-CD3 zeta chain

Egypt Rheumatol Rehabil 46:262-268

(c) 2019 Egyptian Society for Rheumatology and Rehabilitation

$1110-161 X$

\section{Introduction}

Rheumatoid arthritis (RA) is the most common systemic inflammatory disease with articular and extra-articular manifestations [1,2]. It affects $1-2 \%$ of the population worldwide, with women affected 2-3 times more commonly than men [3]. Regarding the etiology of RA, there are many genetic and environmental factors that have associations with the occurrence of RA [4]. Detecting the genetic susceptibility to RA is very challenging. However, many studies identified genetic loci linked to RA such as HLA-DRB1 [5] and cytotoxic T-lymphocyte protein 4 [6]. The initiation and progression of the inflammatory disorder is controlled through the activation and signaling of specific cell surface chemoattractant receptors by their cognate protein ligands, termed chemokines [7].

Over the past two decades, $\mathrm{T}$ cells have become the scope of researches in immunology [8,9]. T cells are the doorkeepers of immune responses toward both foreign and self-antigens. Advances in understanding the pathogenesis of RA confirm the contribution of
$\mathrm{T}$ cells in the disease process through the recognition of the arthritogenic antigen and maintenance of chronic inflammatory response [10]. It is well recognized that $\mathrm{T}$ cells respond to antigen through T-cell receptor (TCR) recognition of MHC-bound peptides on antigen-presenting cells. After identification of a peptide as foreign, a cascade of intracellular signaling takes place, producing both costimulatory molecules and cytokines that will subsequently activate other immune cells. The $T C R-C D 3$ is a multisubunit complex, made up of at least eight transmembrane units. The TCR $\alpha$-chain and $\beta$-chain are essential for antigenspecific recognition [11], whereas CD3 complex $(\delta$, $\varepsilon$, and $\gamma$ ) is involved in signal-transduction pathways through the immunoreceptor tyrosine-based activation motifs [12].

This is an open access journal, and articles are distributed under the terms of the Creative Commons Attribution-NonCommercial-ShareAlike 4.0 License, which allows others to remix, tweak, and build upon the work non-commercially, as long as appropriate credit is given and the new creations are licensed under the identical terms. 


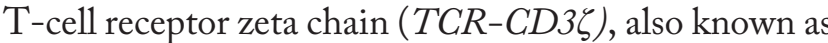
CD247, is responsible for surface expression and signaling steps of the TCR-CD3 complex. CD247 encodes the TCR $\zeta$, a subunit of the T-cell receptor-CD3 complex that may cause inflammatory arthritis in mice if mutated [13]. The zeta chain has a distinguished role in coupling antigen recognition to intracellular signal-transduction pathways. These data were supported by the reported data on $\mathrm{T}$-cell activation and differentiation in RA pathogenesis [14].

Lower expression of CD247 has been found in different diseases including some infection, inflammatory disorders, and malignancy $[15,16]$. As the depressed levels of $T C R-C D 3 \zeta$ are not specific to one particular disease, it remains unclear whether $T C R-C D 3 \zeta$ dysfunction is a primary inciting event or arises as a consequence of chronic inflammatory responses. The initiation and progression of the inflammatory disorder is controlled through the activation and signaling of specific cell surface chemoattractant receptors by their cognate protein ligands, termed chemokines.

Past researches on gene association have reported that

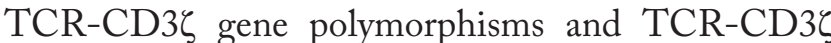
downregulation are associated with various diseases including Crohn's disease, systemic lupus erythematosus [12,17], and systemic sclerosis $[18,19]$. As regards RA, this relationship has not been fully clarified yet as well as its correlation with disease activity was not studied $[14,20,21]$.

Accordingly, we aimed to measure the TCR-CD3 $\zeta$ gene expression profile in a cohort of patients with RA and correlating its expression with disease activity.

\section{Patients and methods}

The study cohort included 150 consecutive RA patients diagnosed according to 2010 ACR/EULAR criteria [22] and recruited between 1 April 2017 and 31 March 2018 from the Rheumatology Outpatient Clinic and Rheumatology Division of the Main Alexandria University Hospital; and 150 matched healthy controls (HC) with no family history of RA or other immune diseases.

Exclusion criteria were RA patients with other autoimmune diseases, viral hepatitis B or C, underlying malignancy, or hematological disorders.

All participants were subjected to full history taking and physical examination, routine laboratory investigations including complete blood count, fasting blood sugar, aspartate transaminases, alanine transaminases, blood urea nitrogen and serum creatinine, inflammatory markers [erythrocyte sedimentation rate (ESR) and quantitative $\mathrm{C}$-reactive protein $(\mathrm{CRP})]$, serological tests [rheumatoid factor (RF) and anti-citrullinated peptide protein antibody (ACPA)], and molecular analysis. Furthermore, RA cases were subjected to disease activity assessment using Disease Activity Score (DAS)-28 and Health Assessment Questionnaire (HAQ) ([23,24].

RF was measured by nephelometry on BN-ProSpec which identifies IgM-RF and the reference range was from 0 to $20 \mathrm{IU} / \mathrm{ml}$ [25], whereas ACPA was tested using enzyme-linked immunosorbent assay and the cutoff for positivity was up to $25 \mathrm{U} / \mathrm{ml}$. ACPA levels then were classified in titer as low for values $25-50 \mathrm{U} / \mathrm{ml}$, moderate for values $50-75 \mathrm{U} / \mathrm{ml}$, and high for values more than $75 \mathrm{U} / \mathrm{ml}[26]$.

\section{Quantitative real-time PCR}

Total RNA was extracted from whole venous blood samples immediately using Pure-Link RNA Mini Kit (Invitrogen Life Technologies, Carlsbad, California, USA).

The extraction procedure was done according to the manufacturer's instructions. Homogenization of the frozen cell pellet was done, followed by binding, washing, and elution of RNA. The quantity and quality were determined by NanoDrop2000 Spectrophotometer (Thermo Scientific, State of California, United States of America) UV absorbance at 260,280 , and $230 \mathrm{~nm}$. A260: A230 ratio greater than 1.7 and A260 : A280 ratio greater than 2.0 were considered indicators for highly pure RNA.

Reverse-transcription PCR for cDNA synthesis was carried out using Invitrogen High Capacity cDNA RT kit (Thermo Fisher Scientific, State of California, United States of America) according to the manufacturer's instructions.

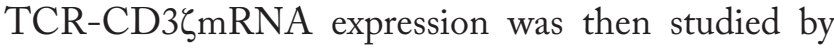
quantitative real-time PCR using TaqMan Gene Expression assay probes on Rotor-Gene Q real-time PCR amplifier (Qiagen, Hilden, Germany), with coamplification of the reference gene B-Actin from the same blood sample as an internal control (TCR-CD3 Hs00609515_m1, B-actin: Hs99999903_M1).

The PCR mixture was $20 \mu 1$ reaction composed of $4 \mu \mathrm{l}$ of cDNA, $10 \mu 1$ TaqMan Gene Expression Master 
Mix, $1 \mu 1$ assay, and $5 \mu 1$ water. The thermal cycling conditions were composed of incubation for $2 \mathrm{~min}$ at $50^{\circ} \mathrm{C}$ followed by incubation at $95^{\circ} \mathrm{C}$ for $10 \mathrm{~min}$ and then $40 \mathrm{PCR}$ cycles of $95^{\circ} \mathrm{C}$ for $15 \mathrm{~s}$ and $60^{\circ} \mathrm{C}$ for 1 min. Each sample on RT-qPCR was analyzed in duplicate. Relative $T C R-C D 3 \zeta \mathrm{mRNA}$ expression was calculated as $2^{-\Delta \Delta C_{\mathrm{t}}}\left(\Delta C_{\mathrm{t}}=C_{\mathrm{t}}\right.$ target- $C_{\mathrm{t}} \beta$-actin) [27].

\section{Statistical analysis}

Data were analyzed using IBM SPSS version 20 [28]. Qualitative data were illustrated using number and percent. Quantitative data were presented using range (minimum and maximum), mean, $\mathrm{SD}$, and median. $P$ value less than 0.05 was accepted as statistically significant. The used statistical tests were: $\chi^{2}$-test (for categorical variables), Student's $t$-test (for normally quantitative variables), Mann-Whitney test (for abnormally quantitative variables), and Spearman's coefficient (to correlate between two abnormally quantitative variables). $P$ value less than 0.05 was interpreted as statistically significant.

The receiver operating characteristic (ROC) curves with the area under the curve (AUC) were used to assess the diagnostic performance of TCR-CD3ל level as a predictor of RA, 'an area $=1.00(100 \%)$ denoting (a gold standard-like) performance, while an area $=0.5$ (50\%) denoting (a chance-like) performance. Significant areas $(P<0.05)$ indicate that the diagnostic performance is significantly better than chance. The cutoff value was chosen as the point that maximizes sensitivity and specificity.

\section{Results}

Participants' demographic data and T-cell receptorCD3 zeta chain gene expression

This study was conducted on 150 RA patients (117 women and 33 men) with a mean age of $30.04 \pm 10.26$ years (RA cases), and 150 (123 women and 27 men) HCs with a mean age of $35.14 \pm 9.12$ years. There was no statistically significant difference between the two groups (RA cases and HC) regarding sex and age $(P<0.05)$, but there was statistically significant difference between both groups regarding $T C R-$ $C D 3 \zeta$ gene expression being lower in the RA group (mean was $0.663 \pm 1.90$ ) than the HC group (mean was $0.816 \pm 1.64)$ as shown in Table 1 .

\section{Correlations}

Measuring the correlation between TCR-CD3 $\zeta$ level and different clinical and laboratory variables assessed in RA patients are shown in Table 2. Assessment of disease activity was performed by applying the DAS (DAS-28/ESR version) and the mean was 3.6 \pm 1.13 , whereas functional state by applying the HAQ and its

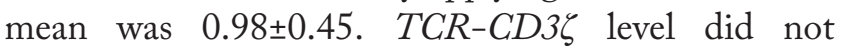
correlate with either DAS-28/ESR, HAQ age of the patients, or duration of morning stiffness.

Although a correlation between two variables does not imply causation, our data showed significant negative correlation between $T C R-C D 3 \zeta$ and disease duration,

Table 2 Correlation between the T-cell receptor-CD3 zeta chain level with different variables in rheumatoid arthritis cases

\begin{tabular}{lcc}
\hline Disease variables & \multicolumn{2}{c}{ CD247 } \\
\cline { 2 - 3 } & $R$ & $P$ \\
\hline Age (years) & 0.138 & 0.338 \\
Disease duration (years) & 0.279 & $0.049^{*}$ \\
Duration of morning stiffness $(\mathrm{min})$ & 0.214 & 0.137 \\
Erythrocyte sedimentation rate $(\mathrm{mm} / \mathrm{h})$ & -0.301 & $0.034^{*}$ \\
C-reactive protein (mg/l) & -0.228 & 0.111 \\
Disease Activity Score-28 & 0.269 & 0.059 \\
Health Assessment Questionnaire score & 0.057 & 0.696 \\
Rheumatoid factor (IU/ml) & -0.314 & $0.026^{*}$ \\
Anti-citrulinated peptide protein antibody $(\mathrm{U} / \mathrm{ml})$ & -0.257 & 0.072 \\
\hline${ }^{*} P \leq 0.05$, statistically significant. & &
\end{tabular}

Table 1 Comparison between rheumatoid arthritis cases and healthy controls regarding demographic characteristics and T-cell receptor-CD3 zeta chain gene expression

\begin{tabular}{|c|c|c|c|c|}
\hline Demographic characteristics & RA cases $(n=150)[n(\%)]$ & $\mathrm{HC}(n=150)[n(\%)]$ & Test of significance & $P$ \\
\hline \multicolumn{5}{|l|}{ Sex } \\
\hline Male & $33(22.0)$ & $27(18.0)$ & $\chi^{2}=0.250$ & 0.617 \\
\hline $\mathrm{F}$ emale & $117(78.0)$ & $123(82.0)$ & & \\
\hline \multicolumn{5}{|l|}{ Age (years) } \\
\hline Minimum-maximum & $20-58$ & $22-56$ & $t=-0.464$ & 0.644 \\
\hline Mean \pm SD & $30.04 \pm 10.26$ & $35.14 \pm 9.12$ & & \\
\hline \multicolumn{5}{|l|}{ TCR-CD3ל } \\
\hline Minimum-maximum & $0.037-12.467$ & $0.034-11.314$ & $Z=-3.047^{*}$ & $0.002^{*}$ \\
\hline Mean \pm SD & $0.663 \pm 1.90$ & $0.816 \pm 1.64$ & & \\
\hline Median (Q1-Q3) & $0.178(0.109-0.314)$ & $0.315(0.198-0.922)$ & & \\
\hline
\end{tabular}

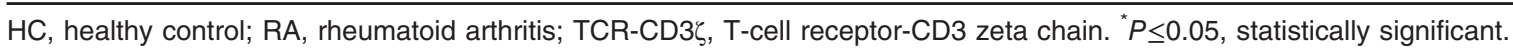


Table 3 Multivariate linear regression for factors affecting T-cell receptor-CD3 zeta chain level in the rheumatoid arthritis group

\begin{tabular}{lccccc}
\hline Disease parameters & $B$ & SE & $\beta$ & $t$ & $P$ \\
\hline Disease duration (years) & 0.047 & 0.065 & 0.093 & 0.716 & 0.478 \\
Erythrocyte sedimentation rate $(\mathrm{mm} / \mathrm{h})$ & 0.010 & 0.010 & 0.150 & 0.999 & 0.323 \\
Rheumatoid factor $(\mathrm{IU} / \mathrm{ml})$ & 0.005 & 0.002 & 0.469 & 2.879 & $0.006^{*}$ \\
\hline
\end{tabular}

${ }^{*} P \leq 0.05$, statistically significant.

Table 4 Relation between the T-cell receptor-CD3 zeta chain level and different variables in the rheumatoid arthritis group

\begin{tabular}{|c|c|c|c|}
\hline Parameters & TCR-CD3 $\zeta($ mean \pm SD) & Test of significance $(Z)$ & $P$ \\
\hline \multicolumn{4}{|l|}{ Sex } \\
\hline Male & $0.849 \pm 1.685$ & -0.023 & 0.981 \\
\hline Female & $0.609 \pm 1.976$ & & \\
\hline \multicolumn{4}{|c|}{ Rheumatoid factor } \\
\hline Positive & $0.092 \pm 0.065$ & -2.235 & $0.025^{\star}$ \\
\hline Negative & $0.712 \pm 1.977$ & & \\
\hline \multicolumn{4}{|c|}{ Anti-citrulinated peptide protein antibody } \\
\hline Positive & $0.330 \pm 0.256$ & -0.791 & 0.429 \\
\hline Negative & $0.708 \pm 2.024$ & & \\
\hline \multicolumn{4}{|c|}{ C-reactive protein } \\
\hline Positive & $0.337 \pm 0.532$ & -1.006 & 0.314 \\
\hline Negative & $0.777 \pm 2.186$ & & \\
\hline
\end{tabular}

TCR-CD3 $\zeta$, T-cell receptor-CD3 zeta chain. ${ }^{*} P \leq 0.05$, statistically significant.

$\mathrm{RF}$, and $\mathrm{ESR}(P<0.05)$. This means, the longer the duration of RA lower the level of TCR-CD3 gene expression, and the higher the value of RF and ESR the lower the level of $T C R-C D 3 \zeta$ gene expression. Moreover, the level of $T C R-C D 3 \zeta$ was negatively correlated with $\mathrm{CRP}$ and ACPA, but did not reach a significant value $(P=0.111$ and 0.072$)$, respectively.

Multivariate linear regression for factors that showed significant negative correlation with the $T C R-C D 3 \zeta$ level in the RA group including disease duration, ESR, and $\mathrm{RF}$ revealed that RF positivity is a predictor of lower level of $T C R-C D 3 \zeta \quad(P<0.05)$ as shown in Table 3.

\section{Relations}

In an attempt to find a causal relation between $T C R-$ $C D 3 \zeta$ level and different variables in RA, Mann-Whitney test was calculated and the data are demonstrated in Table 4. There was a statistically significant relation between the expression of TCR$C D 3 \zeta$ gene and $\mathrm{RF}$ positivity $(P=0.025)$ being less expressed in patients with positive RF. This means that the lower level of $T C R-C D 3 \zeta$ gene expression could be a cause of RF positivity in RA patients.


ACPA positive and CRP positive cases but did not reach a significant level.

\section{Receiver operating characteristic analysis}

Values of TCR-CD3 $\zeta$ were used to construct the ROC curve as shown in the area under the ROC
Figure 1

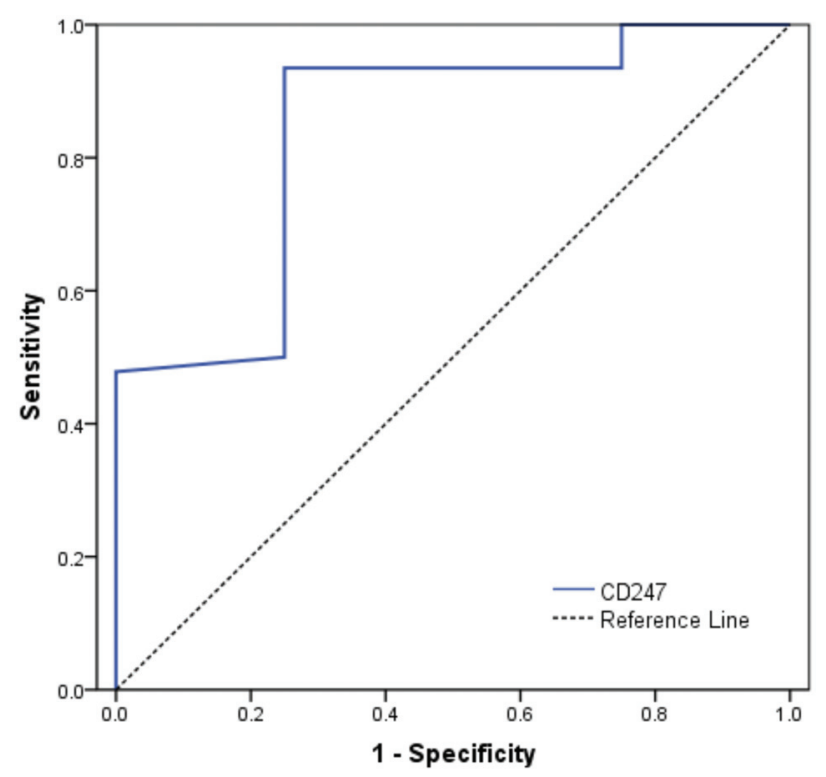

Receiver operating characteristic curve for CD247 (T-cell receptorCD3 zeta chain) level as a predictor of rheumatoid arthritis.

(AUC) curve and the confidence intervals were estimated to examine the accuracy of TCR-CD3 $\zeta$ gene level in discriminating patients with RA from those without RA as shown in Fig. 1. The AUC of the TCR-CD3 $\zeta$ level showed a moderate level of accuracy (AUC $=0.840, P=0.025)$ and the calculated cutoff value $(\leq 0.077)$ can precisely discriminate patients with RA from those without RA with $93.5 \%$ sensitivity and $75 \%$ specificity as shown in Table 5. 
Table 5 Analysis of receiver operating characteristic curve for T-cell receptor-CD3 zeta chain level as a predictor of rheumatoid arthritis

\begin{tabular}{|c|c|c|c|c|c|c|c|c|}
\hline Variable & Cutoff point $(\mathrm{ng} / \mathrm{ml})$ & AUC & $P$ & Sensitivity (\%) & Specificity (\%) & PPV & NPV & Accuracy (\%) \\
\hline TCR-CD3ל & $\leq 0.077$ & $0.840^{*}$ & $0.025^{\star *}$ & 93.5 & 75.0 & 78.9 & 92.0 & 84.3 \\
\hline
\end{tabular}

AUC, area under the curve; NPV, negative predictive value; PPV, positive predictive value; TCR-CD3 $\zeta$, T-cell receptor-CD3 zeta chain.

${ }^{*} A U C \geq 0.5$. ${ }^{* *} P \leq 0.05$, statistically significant.

\section{Discussion}

The CD247 codes for $\mathrm{CD} 3 \zeta$, which is a component of the TCR/CD3 signaling complex on $\mathrm{T}$ cells, and tyrosine phosphorylation of $\mathrm{CD} 3 \zeta$ is one of the first events occurring after TCR engagement [4]. The role of zeta chain is to combine antigen recognition to intracellular signal pathways. Reduced expression of the antigen leads to impaired immune response. Previous studies have suggested that there may be potential errors in the proximal signal-transduction pathway around the TCR-CD3 complex. To date, reviewing the literature has shown limited reported data on TCR-CD3 $\zeta$ gene expression in RA. In this study, we have detected that the expression of the TCR-CD3ל gene is significantly reduced in RA patients compared with $\mathrm{HC}$.

This is in agreement with Matsuda et al. [29], who reported a low expression of $\mathrm{CD} 3 \zeta$ in RA peripheral blood mononuclear cells compared with HC. Moreover, Peng et al. [30] found that CD3ל mRNA levels were downregulated in peripheral blood mononuclear cells of patients with RA when compared with $\mathrm{HCs}$, but partly contradicts the study by Berg et al. [31] who demonstrated through stimulation with anti-CD3 antibodies, a low expression of $\mathrm{CD} 3 \zeta$ in all synovial fluids $\mathrm{T}$ cells of RA cases when compared with peripheral blood $T$ cells, while there was no difference in $\mathrm{CD} 3 \zeta$ expression in $\mathrm{T}$ cells of the peripheral blood between RA patients and HC.Moreover, Maurice et al. [32] found that some events in TCR signaling was clearly reduced in RA synovial fluid $\mathrm{T}$ cells with diminished tyrosine phosphorylation of the TCR 5-chain. This decrease in tyrosine phosphorylation was linked to decreased levels of 5-protein within synovial fluid $\mathrm{T}$ cells. They suggested that a defective TCR signaling contributes the impaired responsiveness of $\mathrm{T}$ cells in the synovial fluid of RA.

Only a few studies had correlated the level of TCR$\mathrm{CD} 3 \zeta$ in RA patients with the disease parameters including the study of Matsuda et al. [29], who reported no association between the patient's CRP and CD3 expression in mononuclear cells of peripheral blood when tested with serum samples in three occasions with 1-month intervals from 10 patients with RA. Their results were in concordance with our results regarding CRP as we found a negative correlation between TCR-CD3 $\zeta$ and CRP but did not reach a significant value. However, we reported a significant negative correlation between TCR-CD3ל level and RA disease duration, RF, and ESR with higher levels of the variables associated with lower levels of TCR-CD3ל mRNA. In this study, the level of $T C R-C D 3 \zeta$ gene expression being negative correlates with, and at the same time significantly relates to RF positivity, which means that the lower expression could be a cause of RF positivity. This might help in understanding the immunopathogenesis of the $\mathrm{RF}$ positive/ACPA negative RA patients. In contrast, a previous study of Mirza et al. [33] concluded that the impaired CD3 in T cells of RA patients showed no correlation with disease duration.

Since changes in the CD3 $\zeta$ chain may affect negatively the internal signaling cascade of the TCR and lead to defective T-cell activation, our observations suggested that CD247 gene downregulation in our cohort of RA cases may contribute in the susceptibility to RA and help comprehending the mechanisms that may lead to deficient T-cell responses in RA patients as well as this downregulation is correlated with disease activity and functional status. Further, we proposed a cutoff point for TCR-CD3 $\zeta$ expression that had good diagnostic accuracy and sensitivity for predicting RA disease. To our knowledge, there are no specific reported values that could be used as reference for TCR-CD3 $\zeta$ expression in RA. We suppose that the presented values could be considered as reference; however, further studies with a larger population should be considered to confirm the current values.

\section{Clinical implementation}

The T-cell receptor T3 zeta chain, CD247, is essential for assembly, surface expression, and signaling cascade of the TCR/CD3 complex. Abnormalities in this pathway can result in $\mathrm{T}$-cell dysfunction and development of autoimmune disorders. Regarding this, previous reports have demonstrated an association of CD247 variants with different autoimmune disorders. This study demonstrated that CD247 was underexpressed among RA than healthy 
patients and detected a cutoff point for TCR-CD3 $\zeta$ expression that had good diagnostic accuracy and sensitivity for predicting RA disease, thus CD247 can be used as a predictor factor for RA occurrence as well as help in predicting the disease course.

\section{Limitations}

This study has some limitations. First, we studied only the CD247 expression not genotyping, so, further studies are needed to assess CD247 genotyping and correlating them with RA activity. Second, we did not assess the changes in the level of TCR-CD3 $\zeta$ with treatment to evaluate its role as a prognostic factor in RA patients. So, longitudinal studies are needed to clarify this point.

\section{Conclusion}

Our results demonstrate a lower level of TCR-CD3ל (CD247) gene expression in RA patients and also correlate with some parameters of the disease activity. The cutoff values for CD247 in RA patients in this study had good diagnostic value in predicting RA patients. These results highlight a pathway in the immunopathogenesis of RA and may open the door for new therapeutic era in disease management that tackles this limb in the pathogenesis. Further multicenter studies with a larger sample size are recommended to validate the exact role of $\mathrm{CD} 247$ gene expression in the pathogenesis of RA.

\section{Acknowledgements}

R.A.E. and A.A.A.: design of the protocol and writing of the manuscript; A.S.I., R.A.E. and A.A.A.: recruitment of the patients, clinical examination and data collection about the disease state; M.G.: performance of PCR and its analysis; A.A.A.: data analysis.

\section{Financial support and sponsorship}

Nil.

\section{Conflicts of interest}

There are no conflicts of interest.

\section{References}

1 Klarenbeek NB, Kerstens PJ, Huizinga TW, Dijkmans BA, Allaart CF. Recent advances in the management of rheumatoid arthritis. BMJ 2010; 341:6942.

2 Chandrashekara S, Shobha V, Dharmanand BG, et al. Reduced incidence of extra-articular manifestations of RA through effective disease control: Karnataka Rheumatoid Arthritis Comorbidity (KRAC) study. Int J Rheum Dis 2017; 20:1694.

3 Alamanos $\mathrm{Y}$, Voulgari PV, Drosos AA. Incidence and prevalence of rheumatoid arthritis, based on the 1987 American College of Rheumatology criteria: a systematic review. Semin Arthritis Rheum 2006; 36:182-188.
4 Abramson SB, Scher JU, Littman DR, Pamer EG, Ubeda C, Longman RS, Sczesnak A, Inventors; Sloan-Kettering Institute for Cancer Research, New York University, Assignee. Causative agents and diagnostic methods relating to rheumatoid arthritis. United States patent application US 2018; 3:883.

5 Kim K, Bang SY, Lee HS, Bae SC. Update on the genetic architecture of rheumatoid arthritis. Nat Rev Rheumatol 2017; 13:13-24.

6 Plenge RM, Padyukov L, Remmers EF, Purcell S, Lee AT, Karlson EW, et al. Replication of putative candidate-gene associations with rheumatoid arthritis in 44000 samples from North America and Sweden: association of susceptibility with PTPN22, CTLA4, and PADI4. Am J Hum Genet 2005; 77:1044-1060.

7 El-Barbary AM, Essa SA, Zaytoun HA. Chemokine receptor CXCR3 in peripheral blood in rheumatoid arthritis patients: its relation to disease activity and joint destruction. Egypt Rheumatol Rehabil 2013; 40:75-75.

8 Crispin JC, Kyttaris VC, Terhorst C, Tsokos GC. T cells as therapeutic targets in SLE. Nat Rev Rheumatol 2010; 6:317-325.

9 Moulton VR, Tsokos GC. Abnormalities of T cell signaling in systemic lupus erythematosus. Arthritis Res Ther 2011; 13:207.

10 Tobon GJ, Youinou P, Saraux A. The environment, geoepidemiology, and autoimmune disease: rheumatoid arthritis. J Autoimmun 2010; 35:10-14.

11 Meuer SC, Cooper DA, Hodgdon JC, Hussey RE, Fitzgerald KA, Schlossman SF, et al. Identification of the receptor for antigen and major histocompatibility complex on human inducer $\mathrm{T}$ lymphocytes. Science 1983; 222:1239-1242.

12 Gorman CL, Russell Al, Zhang Z, Cunningham GD, Cope AP, Vyse TJ. Polymorphisms in the CD3Z gene influence TCR zeta expression in systemic lupus erythematosus patients and healthy controls. J Immunol 2008; 180:1060-1070.

13 Takeuchi T, Suzuki K, Kondo T, Yoshimoto K, Tsuzaka K. CD3 zeta defects in systemic lupus erythematosus. Ann Rheum Dis 2012; 71:i78-i81.

14 Stahl EA, Raychaudhuri S, Remmers EF, Xie G, Eyre S, Thomson BP, et al. Genome-wide association study meta-analysis identifies seven new rheumatoid arthritis risk loci. Nat Genet 2010; 42:508-514.

15 Kono K, Ichihara F, lizuka H, Sekikawa T, Matsumoto Y. Expression of signal transducing $T$-cell receptor molecules after adoptive immunotherapy in patients with gastric and colon cancer. Int $\mathrm{J}$ Cancer 1998; 78:301-305.

16 Seitzer U, Kayser K, Höhn H, Entzian P, Wacker HH, Ploetz S, et al. Reduced T-cell receptor CD3 zeta-chain protein and sustained CD3 expression at the site of mycobacterial infection. Immunology 2001; 104:269-277.

17 Warchoł T, Piotrowski P, Lianeri M, Cies lak D, Wudarski M, Hrycaj P, et al. The CD3Z 844 T4A polymorphism within the 30-UTR of CD3Z confers increased the risk of incidence of systemic lupus erythematosus. Tissue Antigens 2009; 74:68-72.

18 Dieudé $\mathrm{P}$, Boileau C, Guedj M, Avouac J, Ruiz B, Hachulla E, et al. Independent replication establishes the CD247 gene as a genetic systemic sclerosis susceptibility factor. Ann Rheum Dis 2011; 70:1695-1696.

19 Radstake TR, Gorlova O, Rueda B, Martin JE, Alizadeh BZ, PalominoMorales R, et al. Genome-wide association study of systemic sclerosis identifies CD247 as a new susceptibility locus. Nat Genet 2010; 42:426-429.

20 Zhernakova A, Stahl EA, Trynka G, Raychaudhuri S, Festen EA, Franke L, et al. Meta-analysis of genome-wide association studies in celiac disease and rheumatoid arthritis identifies fourteen non-HLA shared loci. PLoS Genet 2011; 7:1002004.

21 Teruel M, McKinney C, Balsa A, Pascual-Salcedo D, Rodriguez L, Ortiz $\mathrm{AM}$, et al. Association of CD247 polymorphisms with rheumatoid arthritis: a replication study and a meta-analysis. PLoS One 2013; 5:68295.

22 Neogi T, Aletaha D, Silman AJ, Funovits J, Felson DT, Bingham CO, et al. The 2010 American College of Rheumatologyl European League Against Rheumatism classification for rheumatoid arthritis. Arthritis Rheum 2010; 62:2582-2591.

23 Van Riel PL. The development of the disease activity score (DAS) and the disease activity score using 28 joint counts (DAS28). Clin Exp Rheumatol 2014; 32:65-74.

24 Wolfe F, Michaud K, Pincus T. Development and validation of the health assessment questionnaire II: a revised version of the health assessment questionnaire. Arthritis Rheum 2004; 50:3296-3305.

25 Roberts-Thomson PJ, Wernick RM, Ziff M. Quantitation of rheumatoid factor by laser nephelometry. Rheumatol Int 1982; 2:17-20. 
26 Coenen D, Verschueren P, Westhovens R, Bossuyt X. Technical and diagnostic performance of 6 assays for the measurement of citrullinated protein/peptide antibodies in the diagnosis of rheumatoid arthritis. Clin Chem 2007; 53:498-504.

27 Livak KJ, Schmittgen TD. Analysis of relative gene expression data using real-time quantitative PCR and the 2(-delta Delta CCT)) method. Methods 2001; 25:402-408.

28 IBM Corp. IBM SPSS Statistics for Windows, version 20.0. Armonk, NY: IBM Corp. 2011.

29 Matsuda M, Ulfgren AK, Lenkei R, Petersson M, Ochoa AC, Lindblad S, et al. Decreased expression of signal-transducing CD3 zeta chains in T cells from the joints and peripheral blood of rheumatoid arthritis patients. Scand $J$ Immunol 1998; 47:254-262.
30 Li P, Wang X, Zhao MQ, Li LJ, Zhang C, Li BZ, et al. TCR-CD3 polymorphisms and expression profile in rheumatoid arthritis, Autoimmunity 2016; 49:466-471.

31 Berg L, Rönnelid J, Klareskog L, Bucht A. Down-regulation of the T cell receptor $\mathrm{CD} 3 z$ chain in rheumatoid arthritis and its influence on $\mathrm{T}$ cell responsiveness. Clin Exp Immunol 2000; 120:174-182.

32 Maurice MM, Lankester AC, Bezemer AC, Geertsma MF, Tak PP, Breedveld FC, et al. Defective TCR mediated signaling in synovial T cells in rheumatoid arthritis. J Immunol 1997; 159:29732978.

33 Mirza NM, Relias V, Yunis EJ, Pachas WN, Dasgupta JD. Defective signal transaction via $\mathrm{T}$-cell receptor-CD3 structure in $\mathrm{T}$ cells from rheumatoid arthritis patients. Hum Immunol 1993; 36:91-98. 